\title{
If I Can't See Well, I Don't Like the Website: Website Design for Both Young and Old
}

\author{
Hyunjoo Im $\cdot$ MiYoung Lee ${ }^{* \dagger}$ \\ Dept. of Design, Housing \& Apparel, University of Minnesota \\ *Dept. of Fashion Design \& Textiles, Inha University \\ Received May 22, 2014; Revised July 21, 2014; Accepted July 22, 2014
}

\begin{abstract}
The increased use of online shopping by older consumers means that online retailers need to consider older consumers when designing websites. We investigated the specific characteristics of commercial websites (i.e., perceptual fluency) through an online experiment. Guided by perceptual fluency and affect optimization literature, hypotheses highlighting older consumers' responses to websites were proposed and tested. Results confirmed that older consumers (in their 50s) are more generous in evaluating online retailers' websites than younger consumers (in their 20s) and that responses to websites are dependent on perceptual fluency. The findings are consistent with previous research and provide additional support for theories that deal with an online apparel shopping context. Practical implications and limitations are discussed.
\end{abstract}

Key words: Perceptual fluency, Affect optimization, Older consumers, Website design, Online shopping

\section{Introduction}

The importance of the older population to the electronic retailing sector continues to grow for two reasons. First, more and more older adults use the Internet and shop online. As of 2012, for the first time in history, more than half (53.0\%) of the older population became Internet users in the US (Span, 2013). The annual growth rate of Internet users among older adults is far greater than that of younger adults (Nielson, 2013). The 2013 Internet Usage Survey in South Korea (Ministry of Sciences, ICT and Future Planning, 2013) revealed that over $80.0 \%$ of the respondents in their $50 \mathrm{~s}, 41.8 \%$ of the respondents in their $60 \mathrm{~s}$, and $11.3 \%$ of the respondents in their $70 \mathrm{~s}$ are Internet users. In particular, the share of new online consumers over the age of 50 is on the rise (Lee, 2013).

Second, this aging trend is making the proportion

\footnotetext{
${ }^{\dagger}$ Corresponding author

E-mail: mylee@inha.ac.kr
}

of older consumers larger than before. The United Nations World Population Aging report (United Nations, Department of Economic and Social Affairs, Population Division, 2013) presented a projection that the older population will more than double by 2050 , from 841 million people to more than 2 billion. Korea is also experiencing an unprecedented aging of its population. The population aged over 65 steadily increased from $7.0 \%$ of the whole population in 2000 to $10.9 \%$ in 2010 , and is expected to reach $32.3 \%$ in 2040 , quickly transitioning Korea to an aged society (Statistics Korea, 2013). As a result, the fashion and retailing industry has recognized older adults as important consumers; still, new fashion brands targeting the elderly and online retailers serving customers aged over 50 have only recently launched (Lee, 2013).

These trends suggest the imminent need for investigating ways that retailers create a comfortable and pleasant online experience for the older population. Shopping is one of the most popular activities for older Internet users (Nielson, 2013). It is known that age-re- 
lated changes in perception, cognition, and motor control affect people's ability to read online. Pew Research recently reported that approximately $40.0 \%$ of seniors experience difficulty in reading due to physical or health conditions (Smith, 2014). Therefore, it is necessary to consider the needs of older consumers when online retailers design their websites.

In response to this problem, the current study investigated a specific characteristic of commercial websites: perceptual fluency. Defined as the ease with which perceptual forms are processed (Reber et al., 1998), perceptual fluency can be used to explain the effect of visual information quality on websites. According to perceptual fluency, easily processed visual stimuli are associated with more positive evaluations than less easily processed visual stimuli (Reber et al., 2004). Although some investigated the outcomes of visual information such as consumers' preferences or choices among different types of visual presentation in online contexts (Choi, 2000; Jang, 2005; You \& Lee, 2010), previous studies have not applied theories to explain how consumers process visual information. In the current study, we propose that perceptual fluency can provide a theoretical explanation for the positive effect of visual information quality in online shopping contexts. Because online shopping has become one of the major shopping channels for fashion products in Korea, it is timely to test the perceptual fluency effect in an online shopping context, where visual information is the primary type of information available to consumers.

Therefore, we conducted an online experiment to illustrate the impact of the perceptual fluency of webpages on consumers' aesthetic evaluations and attitudes, and how the perceptual fluency effect is augmented among older consumers. The results provide valuable insights, particularly for online retailers targeting older consumers.

\section{Literature Review}

\section{Perceptual Fluency Effects}

Perceptual fluency is a subjective feeling of ease with which one processes visual information (Reber et al., 1998). It is characterized by fast, easy, and accurate recognition of visual stimuli. Perceptual fluency is enhanced when a stimulus has characteristics that help viewers' process information fast. For example, a high contrast between the foreground and background enhances the perceptual fluency of a stimulus (Reber et al., 1998) because the high contrast helps people extract information easily from the stimulus. Researchers have also shown that the perceptual fluency of a stimulus can be enhanced by repeated exposure of the stimulus (Huber et al., 2008; Zajonc, 1997) or elongated presentation duration (Reber et al., 1998).

Perceptual fluency has attracted researchers' attention due to its ability to influence preference. Perceptual fluency positively enhances consumers' evaluations and judgments of a target object (e.g., Labroo et al., 2008; Lee \& Labroo, 2004; Reber et al., 1998). When people experience perceptual fluency, they mistakenly attribute this feeling of ease to a feeling of familiarity and liking (Bornstein \& D'Agostino, 1994). The welldocumented effects of perceptual fluency include increased liking, enhanced attitude towards brands (Lee \& Labroo, 2004), heightened preference of a target object (Labroo et al., 2008), and increased truth perception of statements (Reber \& Schwarz, 1999).

Perceptual fluency is deemed to be critical in online environments because users form impressions and make judgments solely based on visual information. Particularly in an online shopping environment, the perceptual fluency of a webpage can influence online shoppers in a way that immediately affects sales. As demonstrated in another context, such as print advertisements (Lee \& Labroo, 2004), high perceptual fluency web pages, typically characterized by high resolution, high contrast pictures and texts, are likely to be evaluated positively in their attractiveness and liking. Directly related to the current study, it was found that online shoppers evaluated a perceptually fluent website as more attractive and pleasant than a less fluent website (Im et al., 2010). Therefore, the following hypothesis is developed:

H1 Perceptual fluency will positively affect consumers' attractiveness evaluations (H1a) of and attitudes (H1b) toward the online shopping site. 


\section{Age and Affect Optimization}

Individuals learn to maintain positive levels of emotion through life experiences by maximizing positive and dampening negative affect (Labouvie-Vief \& Medler, 2002; Lawton et al., 1992). This affect regulation, maximization of positive affect and dampening of negative affect, is called affect optimization, which plays an important role throughout one's life in maintaining a subjective sense of well-being and security (Labouvie-Vief \& Medler, 2002). Individuals achieve affect optimization by organizing and managing social environments so that there is a balance between emotionally stimulating and insulating features and so that they can avoid conflicts and negative affect (Lewis et al., 2010).

Researchers consistently reported that, compared to younger people, older people are more capable of moderating and sustaining positive affect through emotional control and are more capable of lowering stimulation and negative affect, thereby presenting superior self-regulatory capability (Labouvie-Vief \& Medler, 2002; Lawton et al., 1992). In general, older adults have lower levels of negative emotion, concern and anger, compared to younger adults. Furthermore, older adults have higher levels of satisfaction with life than their younger counterparts (Blazer, 2003). Therefore, it is suggested that older adults may respond more positively to the same object or event than younger adults because older adults regulate their affect constantly in order to maintain a positive level.

There is also some evidence that age positively biases the consumer decision-making process, such as information seeking and evaluation. Older people tend to attend only to positive stimuli, while avoiding negative stimuli. In a laboratory experimental study, older adults directed their attention away from negative stimuli and toward positive stimuli, while younger adults did not show this bias (Isaacowitz et al., 2006; Mather \& Carstensen, 2003; Mather et al., 2005). Also, older persons are more likely to evaluate products positively and to be more satisfied with purchases than younger persons. As opposed to younger people, older people are found to prefer products with positive attributes more strongly and are likely to show less regret over purchases (Kim et al., 2008); moreover, they tend to experience more positive emotions after purchasing products (Birditt \& Fingerman, 2003, 2005). Researchers also found that consumers' quality evaluations and satisfaction increase with age (Chan et al., 2003; Charles \& Carstensen, 2008). It was found that the older adults minimize conflict through positive evaluations, whereas younger adults tend to make more negative evaluations (Charles \& Carstensen, 2008). Thus, it is likely that older adults will evaluate commercial websites more positively than younger adults, in general. The rationale above is reflected in $\mathrm{H} 2$ :

H2 Age will positively affect consumers' attractiveness evaluation of $(\mathrm{H} 2 \mathrm{a})$ and attitude $(\mathrm{H} 2 \mathrm{~b})$ toward the website. Specifically, the older participants, compared with the younger participants, will rate the website to be more attractive and will show more positive attitudes toward the online shopping site.

\section{Age and Visual Processing}

Visual impairment is a result of the normal process of aging. It has been noted that individuals' capability to process visual information, particularly selective attention to visual information, declines as they grow older (Plude \& Hoyer, 1986). It was also found that mature consumers find it difficult to extract information and to complete visually oriented tasks (Griffiths \& Harmon, 2011). Moreover, two major components of visual ability, visual acuity and contrast sensitivity, deteriorate as people grow older (Wood, 2002). Visual acuity concerns clearness of vision and is a quantified measure of overall vision. Contrast sensitivity involves the ability to distinguish and successfully extract information in the foreground from the background. Thus, the aging process involves loss of clarity in vision, as well as one's ability to process low-contrast visual information (e.g., light grey letters on a white background).

Online shopping heavily involves visually-oriented tasks. Unlike the traditional shopping channel, where consumers can evaluate merchandise by touching and feeling it, consumers are left with visual information alone provided by retailers. Older consumers who do 
not have as acute vision as younger consumers may experience more difficulty processing visual information presented online. The pictures and texts that young consumers have no problem processing can be perceived as difficult to read for older consumers. For example, young consumers may be able to read grey text against a white background, while older consumers may not be able to detect the contrast as easily.

Therefore, it is likely that older consumers will benefit more from high perceptual fluency of a website than younger consumers. When website visual elements are hard to process, it will affect both young and old consumers negatively. However, because of younger consumers' higher ability to process online visual information, a website with low perceptual fluency will not affect them as much as older consumers. Consistently, when a website is highly fluent, it is likely that both young and old consumers will positively respond to it. However, older consumers are more likely to appreciate the easy experience than younger consumers. Therefore, it is hypothesized that age will moderate the perceptual fluency effect on attractiveness and attitude evaluation. We predict that older consumers (vs. younger consumers) will exhibit a larger change in their attitude and attractiveness rating, depending on the level of perceptual fluency.

H3 The main effect of perceptual fluency on attractiveness (H3a) and attitude (H3b) will be moderated by age. Specifically, the perceptual fluency effect on attractiveness and attitude toward the online shopping site will be stronger for older consumers than for younger consumers.

\section{Control Variables: Fashion Involvement and Online Shopping Efficacy}

Two control variables, fashion involvement and online shopping efficacy, were considered in this study because these personality variables can potentially mask the effects of the variables of interests: age and perceptual fluency.

\section{1) Fashion Involvement}

Involvement, the perceived importance or relevance of a target to individuals, is an enduring construct, and consumers have different levels of involvement toward a product category (Zaichkowsky, 1986). Fashion involvement is particularly important in determining consumers' motivation to process fashion-related information, and subsequently form attitudes and beliefs. Consumers with high fashion involvement may have greater interest for fashion products and are more likely to engage in frequent clothing shopping than those with average or low involvement (O'Cass, 2004). Also, consumers with high involvement are willing to invest time and effort to process related information (Petty et al., 1983).

\section{2) Online Shopping Efficacy}

Self-efficacy is a form of self-evaluation reflecting subjective beliefs and confidence in one's own capability to perform a task (Pappas et al., 2014). Self-efficacy is domain-specific (Bandura, 1997) and researchers have defied Internet self-efficacy (Wei \& Zhang, 2008) or online shopping self-efficacy in the context of online shopping (Hill \& Beatty, 2011). It has been found that self-efficacy influences an individual's coping strategies in retail environments (Tsarenko \& Strizhakova, 2013). It was found that self-efficacy plays an important role in understanding online consumer satisfaction and loyalty intention (Lee et al., 2009), and purchases (Hernandez et al., 2009).

\section{Methods}

\section{Measurements}

All measurement items were adopted from previous studies and reworded to reflect the current study context when necessary. Website attractiveness was measured with the appearance subscale of the perceived website quality scale (Aladwani \& Palvia, 2002). Attitude toward the website was measured with two items adopted from Lee et al. (2008). Manipulation of perceptual fluency was checked with two items (perceived visual quality and perceived readability). Because the context of the current study was apparel online shopping, fashion involvement and Internet shopping efficacy were also measured to control for 
any potential confounding effects. Fashion involvement was measured with four items (Fairhurst et al., 1989) and Internet shopping efficacy was measured with six items adopted from Eastin and Larose (2000). Demographic variables such as age and education level, as well as apparel shopping behaviors, were also measured at the end.

\section{Study Design}

The current study employed a 2 (perceptual fluency: High vs. Low) $\times 2$ (age: 50 s vs. 20 s) between-subjects factorial design. Perceptual fluency was manipulated through image manipulation. Six high-quality product pictures, bigger than $300 \times 300$ pixels and with high contrast between the item and its background, were selected for the experiment. These pictures were subsequently manipulated to reduce perceptual fluency by decreasing contrasts between the foreground and background and by reducing the resolution of the images. Manipulation of the perceptual fluency factors was confirmed through a pretest using undergraduate students $(N=58) . T$-tests revealed that the high perceptual fluency website $(n=30)$ was perceived to be more readable $(M=3.57$ vs. $2.10 ; t=-5.552, p<.001)$ and of higher image quality ( $M=3.17$ vs. $2.00 ; t=-5.378$, $p<.001)$ than the low perceptual fluency website ( $n=$ 28).

For the experiment, consumer panel data of two age groups, participants in their $20 \mathrm{~s}$ and $50 \mathrm{~s}$, were targeted and purchased in South Korea. The 20s and 50s age groups represent the younger and older consumers, respectively. People in their 50s were targeted because they are relatively active in using the Internet for daily activities and shopping among older consumer groups (Lee, 2013; Ministry of Sciences, ICT and Future Planning, 2013). Because the study context was for an online retailer targeting females, only females were recruited. For each age group, at least 60 responses were collected for each condition, and the participants were randomly assigned to one of the two treatment conditions (high vs. low fluency) to evaluate six apparel items. The online survey was conducted for a week in December 2013.

A total of 247 females (122 in their 20s, 125 in their
Table 1. Samples in experimental conditions

\begin{tabular}{c|c|c|c}
\hline \hline \multirow{2}{*}{} & \multicolumn{2}{|c|}{ Perceptual fluency } & \multirow{2}{*}{ Total } \\
\cline { 2 - 3 } & High & Low & \\
\hline Young (20s) & 60 & 62 & 122 \\
\hline Old (50s) & 63 & 62 & 125 \\
\hline Total & 123 & 124 & 247 \\
\hline
\end{tabular}

50s) with online shopping experience participated in the study. As presented in $<$ Table 1 $>$, participants were randomly assigned to one of the two perceptual fluency conditions.

\section{Results}

The data were analyzed using SPSS 20.0. The majority of the younger participants (in their 20s) were students $(59.8 \%)$ or white-collar workers (18.0\%). In terms of education, $54.9 \%$ had high school degrees or were currently enrolled in college, and $39.3 \%$ had college degrees. The majority of the older participants (in their 50s) were housewives (60.0\%), and $47.2 \%$ had college degrees, while $44 \%$ had high school degrees. All participants had online shopping experience, and the vast majority $100.0 \%\left(N_{\text {young }}=122\right)$ of the younger participants and $92.8 \%\left(N_{\text {old }}=116\right)$ of the older participants) had purchased apparel items online in the past. Apparel items were the most popular category that the participants shopped for online, accounting for $36.8 \%\left(N_{\text {old }}=46\right)$ and $66.4 \%\left(N_{\text {young }}=81\right)$ of online shopping for the older and younger groups, respectively. When shopping for apparel items online, the participants spent $\$ 65$ per transaction, on average: the younger group spent an average of $\$ 60.20$, while the older group spent an average of $\$ 69.66$. For apparel shopping, both young and old participants reported the online channel as the most preferred retail channel $\left(N_{\text {old }}\right.$ $=51,40.8 \%$; $N_{\text {young }}=84,68.9 \%$; overall $54.66 \%$ of the total participants), followed by department stores ( $N_{\text {old }}$ $=30,24 \% ; N_{\text {young }}=18,14.8 \%$; overall $19.43 \%$ of the total participants). Approximately $74.6 \%$ of the younger participants and $70.4 \%$ of the older participants browse fashion online stores at least once a week. Also, $74.6 \%$ of younger participants and $52.0 \%$ of the older participants purchase fashion items from online stores at least once a month. It is surprising that more 
than $40.0 \%$ of the participants in their $50 \mathrm{~s}$ indicated that their most preferred retail format for fashion items is online stores, and they browse online stores for fashion items as often as people in their 20 s do. This finding confirms the increase of older consumers' participation in online shopping and provides further support for the need to understand the online shopping behavior of mature consumers.

\section{Hypotheses Testing}

Measurement reliabilities for all of the measurement items were first evaluated. A factor analysis with all items was performed to check whether the measures had good discriminant validity. All items were loaded on corresponding factors, thus confirming the discriminant validity of the measurement items. All measurement inter-item reliabilities were good (Cronbach's alpha $>.80$ ) and were averaged to single scores. Two items measuring product attractiveness and liking were averaged into a product evaluation index score for each product. The control variables, fashion involvement and online shopping self-efficacy, were evaluated for correlations with dependent measures. Fashion involvement was found not to be significantly related to the dependent measures. On the other hand, online shopping self-efficacy was found to be significantly related to some dependent measures; thus, it was included in the analysis as a covariate.

The manipulation of perceptual fluency was first examined using ANOVA. Perceptual fluency was successfully manipulated. The high perceptual fluency website was perceived to be more readable $\left(M_{\mathrm{H}}=3.59\right.$ vs. $\left.M_{\mathrm{L}}=2.91 ; F(1,245)=51.13, p<.001\right)$ and to have higher image quality $\left(M_{\mathrm{H}}=3.17\right.$ vs. $M_{\mathrm{L}}=2.14 ; F(1,245)$ $=134.60, p<.001$ ) than the low perceptual fluency website. Hypotheses were tested using MANCOVA with perceptual fluency and age as independent variables and attitude and attractiveness as the dependent variables. The test results of MANCOVA are presented in $<$ Table $2>$. The multivariate test results confirmed that online shopping efficacy is a significant covariate for the model $\left(F(2,241)=4.15, p=.02\right.$, partial $\left.\eta^{2}=.03\right)$. Importantly, the effects of perceptual fluency $(F(2,241)=$ $7.39, p=.001$, partial $\left.\eta^{2}=.06\right)$ and age $(F(2,241)=30.04$, $p=.000$, partial $\left.\eta^{2}=.20\right)$ on website attractiveness and

Table 2. Test results of MANCOVA

\begin{tabular}{|c|c|c|c|c|c|c|c|}
\hline & Dependent Variable & Source & Wilk's Lambda & df & $F$ & Sig. & Partial eta $^{2}$ \\
\hline \multirow{4}{*}{ Multivariate tests } & & Efficacy & .97 & 2,241 & 4.15 & .02 & .03 \\
\hline & & Fluency & .94 & 2,241 & 7.39 & .00 & .06 \\
\hline & & Age & .80 & 2,241 & 30.04 & .00 & .20 \\
\hline & & Fluency $\times$ Age & .97 & 2,241 & 3.78 & .02 & .03 \\
\hline \multirow{12}{*}{ Univariate tests } & \multirow{6}{*}{ Attitude $^{a}$} & Fluency & & 1 & 7.81 & .01 & .03 \\
\hline & & Age & & 1 & 45.75 & .00 & .16 \\
\hline & & Fluency $\times$ Age & & 1 & 5.13 & .02 & .20 \\
\hline & & Error & & 242 & & & \\
\hline & & Total & & 247 & & & \\
\hline & & Corrected Total & & 246 & & & \\
\hline & \multirow{6}{*}{ Attractiveness $^{\mathrm{b}}$} & Fluency & & 1 & 14.70 & .00 & .06 \\
\hline & & Age & & 1 & 53.60 & .00 & .18 \\
\hline & & Fluency $\times$ Age & & 1 & .09 & .76 & .00 \\
\hline & & Error & & 242 & & & \\
\hline & & Total & & 247 & & & \\
\hline & & Corrected Total & & 246 & & & \\
\hline
\end{tabular}

a: $R^{2}=.269$ (Adjusted $R^{2}=.257$ )

b: $R^{2}=.277$ (Adjusted $R^{2}=.265$ ) 
attitude were statistically significant.

Further univariate test results were evaluated for the main and interaction effects of perceptual fluency and age on each dependent variable. Perceptual fluency had a significant effect on both website attractiveness $\left(F(1,242)=14.70, p=.000\right.$, partial $\left.\eta^{2}=.06\right)$ and attitude toward the website $(F(1,242)=7.81, p=.006$, partial $\eta^{2}=.03$ ). As expected, participants in the low perceptual fluency condition (vs. high perceptual fluency condition) perceived the website as less attractive $\left(M_{\mathrm{L}}=2.61\right.$ vs. $\left.M_{\mathrm{H}}=2.91\right)$ and showed a less positive attitude toward the website $\left(M_{\mathrm{L}}=2.16\right.$ vs. $M_{\mathrm{H}}=$ 2.44). Therefore, H1a and H1b were both supported. Consistent with $\mathrm{H} 2$, there was a significant difference in the website attractiveness evaluations $(F(2,242)=$ 53.60, $p=.000$, partial $\left.\eta^{2}=.18\right)$ and attitude $(F(2,242)$ $=45.75, p=.000$, partial $\eta^{2}=.16$ ) between the two age groups. Specifically, the older participants evaluated the website attractiveness more positively $\left(M_{\mathrm{L}}=2.45\right.$ vs. $M_{\mathrm{H}}=3.06$ ), and formed more positive attitudes toward the website than the younger participants $\left(M_{\mathrm{L}}=\right.$ 1.94 vs. $M_{\mathrm{H}}=2.65$ ). Thus, $\mathrm{H} 2 \mathrm{a}$ and $\mathrm{H} 2 \mathrm{~b}$ were supported. Lastly, H3 hypothesized a significant interaction effect of perceptual fluency and age. This hypothesis was partially supported. The interaction was significant for attitude $(F(2,242)=5.13, p=.024$, partial $\eta^{2}=.02$ ), but not for website attractiveness $(F$ $(2,242)=.09, p=.76)$. As hypothesized, the increase in positive attitude due to perceptual fluency among the older participants $\left(M_{\mathrm{L}}=2.40\right.$ to $\left.M_{\mathrm{H}}=2.90\right)$ was more
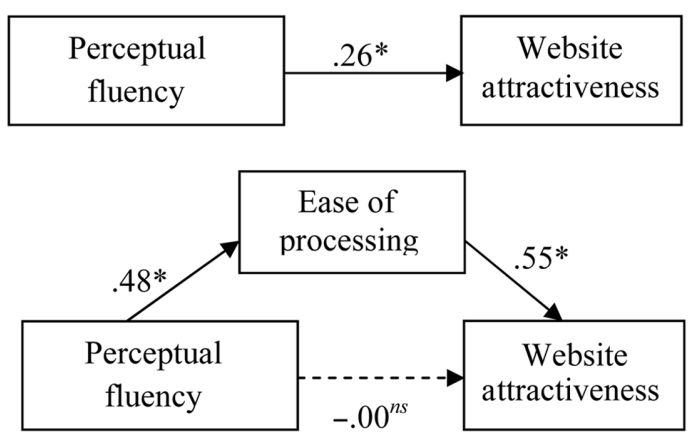

Older participants prominent than among the younger participants $\left(M_{\mathrm{L}}=\right.$ 1.91 to $M_{\mathrm{H}}=1.97$ ) (Fig. 1). However, there was no significant difference between age groups in terms of its increase in attractiveness (young: $M_{\mathrm{L}}=2.32$ to $M_{\mathrm{H}}$ $=2.59$, old: $M_{\mathrm{L}}=2.89$ to $M_{\mathrm{H}}=3.22$ ). Thus, only H3b was supported.

The reason H3a was not supported could be that the fluency experience may affect attitude beyond immediate attractiveness more for the older participants than for the younger participants. To examine the strength of the perceptual fluency effect, two mediation analyses for the two age groups were conducted. The results show that the effect of website perceptual fluency is fully mediated by perceived readability of the website (i.e., feeling of easy processing). Also, it was confirmed that website perceptual fluency has a stronger effect among the older population than the younger population (Fig. 2). The summary of hypotheses test results are presented in $<$ Table $3>$.

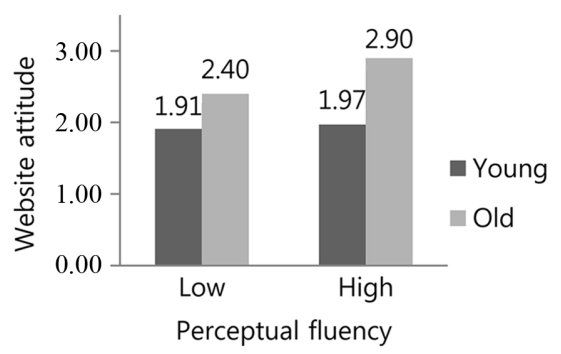

Fig. 1. Attitude toward the website score by perceptual fluency and age.
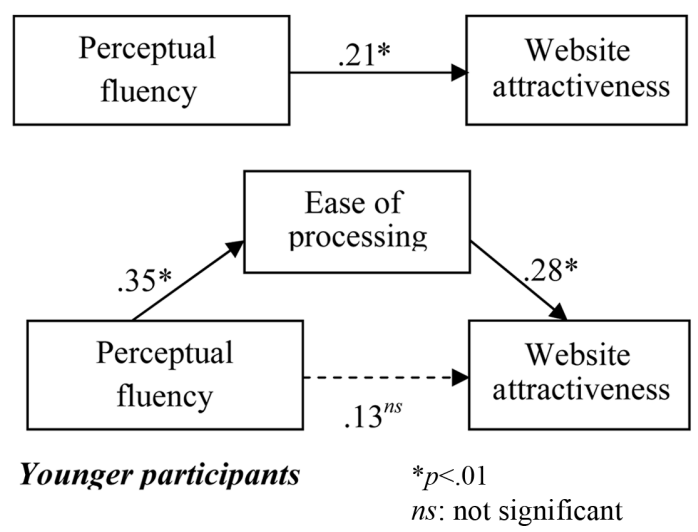

Fig. 2. Mediation analysis results. 
Table 3. Summary of hypotheses test results

\begin{tabular}{c|l|c}
\hline \hline \multirow{2}{*}{ H1 } & \multicolumn{1}{|c|}{ Hypotheses } & Support \\
\cline { 2 - 3 } & H1a Perceptual fluency will positively affect a consumers' attractiveness evaluation of an online shopping site. & Yes \\
\hline \multirow{2}{*}{ H2 } & H2a Age will positively affect a consumers' attractiveness evaluation of a website. & Yes \\
\cline { 2 - 3 } & H2b Age will positively affect a consumers' attitude toward a website. & Yes \\
\hline \multirow{2}{*}{ H3 } & H3a The main effect of perceptual fluency on attractiveness will be moderated by age. & Yes \\
\cline { 2 - 4 } & H3b The main effect of perceptual fluency on attitude will be moderated by age. & No \\
\hline
\end{tabular}

\section{Discussion and Implications}

\section{Perceptual Fluency Effect on Online Consu- mer Evaluations of Websites}

The current study investigated the effects of the perceptual fluency of websites on consumers' attractiveness evaluations and attitudes. The results confirmed the hypotheses stating that the high perceptual fluency of websites positively affect online consumers, providing additional support for the perceptual fluency literature. Compared to the low perceptual fluency website, the high perceptual fluency website was more liked and perceived as more attractive, regardless of the age of the participants. This is consistent with the perceptual fluency literature, which states the positive effect of perceptual fluency on consumers' aesthetic evaluations and judgments (Lee \& Labroo, 2004; Reber et al., 1998), and the processing fluency literature, which states that the experience of information processing ease positively affects consumers' evaluations (Alter \& Oppenheimer, 2009).

More importantly, the current study investigated the interaction between age and perceptual fluency. It was hypothesized that older consumers would respond to perceptual fluency more strongly than younger consumers because of older consumers' lowered capability to process online visual information. Thus, older age is proposed to exaggerate the perceptual fluency effect. Consistent with this rationale, older consumers were more affected by the perceptual fluency of the stimulus website than younger consumers. The older participants, as opposed to the younger participants, formulated significantly more positive attitudes toward the high perceptual fluency website than the low perceptual fluency website. We also hypothesized that the moderating effect of age would be significant for attractiveness evaluations of the website. However, the result failed to find a significant interaction effect of age and perceptual fluency on attractiveness evaluations. This may mean that the immediate aesthetic evaluation of a stimulus derived from perceptual fluency is equally effective for both young and old groups, but a feeling of ease affects positive attitudes and evaluations toward websites more for older people than younger people. Another possible explanation is a ceiling effect. Because younger consumers are accustomed to more complex and stimulating online store designs, even the high fluency website stimulus used in this study could have been still relatively simple. This, in turn, could have negatively affected their evaluations of attractiveness because they might prefer more complex and interesting designs in general. The results provide additional insights for understanding the perceptual fluency effect in an online shopping context. Particularly, the heightened importance of perceptual fluency among older consumers provides a valuable insight for online information presentation.

\section{Older Consumers Are More Generous}

Consistent with the affect optimization literature (Labouvie-Vief \& Medler, 2002; Lawton et al., 1992), the results showed that the older participants evaluated the stimulus websites more positively, both with respect to attractiveness and attitude, than their younger counterparts. According to the literature, older persons are better at regulating their emotional experiences in responding to external events, and are generally more capable of maintaining positive levels of affect than younger persons. Therefore, the same websites could produce more positive responses from ol- 
der participants than from younger participants. This result is consistent with previous studies, which have found that older consumers are more positive in evaluating products and purchases than younger consumers (Birditt \& Fingerman, 2003, 2005; Chan et al., 2003; Kim et al., 2008).

\section{Implications}

Since the online channel has become one of the major retail channels in Korea, many have investigated the methods or outcomes of online stores' visual information presentation (e.g., consumers' preferences of visual presentation in online stores). However, not much research has employed theories explaining the underlying process of how consumers process visual information in online stores. This study suggests that the perceptual fluency of visual information on the Web induces positive attitudes and evaluations toward targeted fashion items.

The findings of the current study provide practical implications for online apparel retailers. The positive perceptual fluency effect on online consumers' evaluations of website attractiveness and their attitudes toward the website implies that online retailers should consider the level of the perceptual fluency of images on their websites. Many online retailers post manufacturers' images that are sometimes blurry and small. In particular, it is important to evaluate their picturebackground contrast level, as white products against a white background will reduce perceptual fluency. Also, the color of text on the website should stand out from the background clearly enough. The current study suggests that this effect of perceptual fluency can be critical for apparel brands that target more mature populations. The effect of high perceptual fluency on attitudes toward a website was magnified for older consumers, suggesting the importance of visual information presentation for older consumers. As older online consumers grow in their numbers, this finding implies that perceptual fluency should be a critical consideration for designing websites, in general. Lastly, it was found that younger consumers are more critical in evaluating websites than older consumers, generally giving them lower scores. This may suggest that it is important to make the online experience of younger consumers pleasant and seamless because a small flaw can greatly affect their perceptions of a website experience.

\section{Limitations and Future Study Suggestions}

We recognize a few limitations of the current study. We selected two age groups purposefully (20s and 50s) and compared them, while using participants' online shopping efficacy as a covariate. Although we found evidence for older consumers' preference for perceptual fluency, it would be fruitful to study consumers within a wider range of ages. Also, for future research, other consumer characteristics, such as consumers' style of processing (visual/verbal), experiential value or shopping orientation, could be evaluated together. For instance, since perceptual fluency is closely tied to emotional responses, hedonically oriented consumers, compared to utilitarian oriented consumers, may be more likely to be influenced by the perceptual fluency level. In addition, only one type of product - apparel - was used for the experiment in this study. Replicating the study using different product categories or characteristics could deepen our understanding of this phenomenon. The perceptual fluency effect might be stronger for hedonic products (e.g., dress) than for utilitarian products (e.g., computer). Even within the clothing category, the perceived value derived from a product may influence the strength of the perceptual fluency effect (e.g., a dress for a special occasion vs. a functional outdoor jacket). Lastly, unlike normal retailers' websites, the stimulus website we developed had a small number of products on a single webpage. In order to provide a more real online shopping experience to the research participants, a mock retailer's website with an expanded product assortment and numerous pages could be used in the future.

Several possible future study ideas were developed from a review of the literature. Previous research found that fluency creates a positive emotional reaction, and this positive reaction creates a sense of familiarity, more positive evaluations, and facilitates recognition. For a deeper understanding, additional research invol- 
ving the effect of perceptual fluency on emotional reaction, evaluation, and behavioral intent is needed. From the literature regarding older adults and affect optimization, older consumers tend to attend more to positive stimuli and to emotional meaning (Carstensen et al., 1999). Because research on older consumers' online store behavior is limited, research on how older consumers process different online product information can be valuable, such as formats (visual vs. verbal), valence (positive/negative) or characteristics (emotional/informational).

\section{References}

Aladwani, A. M., \& Palvia, P. C. (2002). Developing and validating an instrument for measuring user-perceived web quality. Information \& Management, 39(6), 467476.

Alter, A. L., \& Oppenheimer, D. M. (2009). Uniting the tribes of fluency to form a metacognitive nation. Personality and Social Psychology Review, 13(3), 219-235.

Bandura, A. (1997). Self-efficacy: The exercise of control. New York: WH Freeman.

Birditt, K. S., \& Fingerman, K. L. (2003). Age and gender differences in adults' descriptions of emotional reactions to interpersonal problems. The Journals of Gerontology Series B: Psychological Sciences and Social Sciences, 58(4), P237-P245.

Birditt, K. S., \& Fingerman, K. L. (2005). Do we get better at picking our battles? Age group differences in descriptions of behavioral reactions to interpersonal tensions. The Journals of Gerontology Series B: Psychological Sciences and Social Sciences, 60(3), 121-128.

Blazer, D. G. (2003). Depression in late life: Review and commentary. The Journals of Gerontology Series A: Biological Sciences and Medical Sciences, 58(3), M249M265.

Bornstein, R. F., \& D'Agostino, P. R. (1994). The attribution and discounting of perceptual fluency: Preliminary tests of a perceptual fluency/attributional model of the mere exposure effect. Social Cognition, 12(2), 103-128.

Carstensen, L. L., Isaacowitz, D. M., \& Charles, S. T. (1999). Taking time seriously: A theory of socioemotional selectivity. American Psychologist, 54(3), 165-181.

Chan, L. K., Hui, Y. V., Lo, H. P., Siu, K. T., Tso, G. K., \& Wu, M. L. (2003). Consumer satisfaction index: new practice and findings. European Journal of Marketing, 37(5/6), 872-909.

Charles, S. T., \& Carstensen, L. L. (2008). Unpleasant situations elicit different emotional responses in younger and older adults. Psychology and Aging, 23(3), 495-504.

Choi, E. Y. (2000). The effect of presentation methods of apparel products on the Internet on purchase decision making. Journal of the Korean Society of Costume, 50(5), 103-115.

Eastin, M. S., \& Larose, R. (2000). Internet self-efficacy and the psychology of the digital divide. Journal of Computer-Mediated Communication, 6(1). doi:10.1111/j.10836101.2000.tb00110.x

Fairhurst, A. E., Good, L. K., \& Gentry, J. W. (1989). Fashion involvement: An instrument validation procedure. Clothing and Textiles Research Journal, 7(3), 10-14.

Griffiths, M. A., \& Harmon, T. R. (2011). Aging consumer vulnerabilities influencing factors of acquiescence to informed consent. Journal of Consumer Affairs, 45(3), 445466.

Hernandez, B., Jimenez, J., \& Martin, M. J. (2009). The impact of self-efficacy, ease of use and usefulness on epurchasing: An analysis of experienced e-shoppers. Interacting with Computers, 21(1/2), 146-156.

Hill, W. W., \& Beatty, S. E. (2011). A model of adolescents' online consumer self-efficacy (OCSE). Journal of Business Research, 64(10), 1025-1033.

Huber, D. E., Clark, T. F., Curran, T., \& Winkielman, P. (2008). Effects of repetition priming on recognition memory: Testing a perceptual fluency-disfluency model. Journal of Experimental Psychology: Learning, Memory, and Cognition, 34(6), 1305-1324.

Im, H., Lennon, S. J., \& Stoel, L. (2010). The perceptual fluency effect on pleasurable online experience. Journal of Research in Interactive Marketing, 4(4), 280-295.

Isaacowitz, D. M., Wadlinger, H. A., Goren, D., \& Wilson, H. R. (2006). Selective preference in visual fixation away from negative images in old age? An eye-tracking study. Psychology and Aging, 21(1), 40-48.

Jang, E. Y. (2005). A comparative analysis of components on web sites by the types of Internet apparel shopping malls in Korea. Journal of the Korean Society of Costu$m e, 55(6), 76-92$.

Kim, S., Healey, M. K., Goldstein, D., Hasher, L., \& Wiprzycka, U. J. (2008). Age differences in choice satisfaction: a positivity effect in decision making. Psychology of Aging, 23(1), 33-38.

Labouvie-Vief, G., \& Medler, M. (2002). Affect optimization and affect complexity: Modes and styles of regulation in adulthood. Psychology and Aging, 17(4), 571-588.

Labroo, A. A., Dhar, R., \& Schwarz, N. (2008). Of frog wines and frowning watches: Semantic priming, perceptual fluency, and brand evaluation. Journal of Consumer Research, 34(6), 819-831.

Lawton, M. P., Kleban, M. H., Rajagopal, D., \& Dean, J. (1992). Dimensions of affective experience in three age groups. Psychology and Aging, 7(2), 171-184. 
Lee, A. Y., \& Labroo, A. A. (2004). The effect of conceptual and perceptual fluency on brand evaluation. Journal of Marketing Research, 41(2), 151-165.

Lee, H., Choi, S. Y., \& Kang, Y. S. (2009). Formation of esatisfaction and repurchase intention: Moderating roles of computer self-efficacy and computer anxiety. Expert Systems with Applications, 36(4), 7848-7859.

Lee, K. Y., Sung, J. Y., \& Jun, S. K. (2008). Effects of interactivity of Internet sponsorship on the website attitude. Journal of Marketing Management Research, 13(3), 2135.

Lee, R. (2013, October 24). Online shops target baby boomers. The Korea Times. Retrieved January, 23, 2014, from http://www.koreatimesus.com/?p=1124

Lewis, M., Haviland-Jones, J. M., \& Barrett, L. F. (Eds.). (2010). Handbook of Emotions. New York: Guilford Press.

Mather, M., \& Carstensen, L. L. (2003). Aging and attentional biases for emotional faces. Psychological Science, 14(5), 409-415.

Mather, M., Knight, M., \& McCaffrey, M. (2005). The allure of the alignable: Younger and older adults' false memories of choice features. Journal of Experimental Psychology: General, 134(1), 38-51.

Ministry of Sciences, ICT and Future Planning. (2013). 2013 Internet usage survey. Ministry of Sciences, ICT and Future Planning. Retrieved April 15, 2014, from http:// www.msip.go.kr/www/brd/m_211/view.do?seq=1142

Nielson, J. (2013, May 28). Seniors as web users. Nielsen Norman Group. Retrieved April 15, 2014, from http:// www.nngroup.com/articles/usability-for-senior-citizens/

O'Cass, A. (2004). Fashion clothing consumption: Antecedents and consequences of fashion clothing involvement. European Journal of Marketing, 38(7), 869-882.

Pappas, I. O., Pateli, A. G., Giannakos, M., \& Chrissikopoulos, V. (2014). Moderating effects of online shopping experience on customer satisfaction and repurchase intentions. International Journal of Retailing \& Distribution Management, 42(3), 187-204.

Petty, R. E., Cacioppo, J. T., \& Schumann, D. (1983). Central and peripheral routes to advertising effectiveness: The moderating role of involvement. Journal of Consumer Research, 10, 135-146.

Plude, D. J., \& Hoyer, W. J. (1986). Age and the selectivity of visual information processing. Journal of Psychology and Aging, 1(1), 4-10.

Reber, R., \& Schwarz, N. (1999). Effects of perceptual fluency on judgments of truth. Consciousness and Cognition, 8(3), 338-342.
Reber, R., Schwarz, N., \& Winkielman, P. (2004). Processing fluency and aesthetic pleasure: Is beauty in the perceiver's processing experience? Personality and Social Psychology Review, 8(4), 364-382.

Reber, R., Winkielman, P., \& Schwarz, N. (1998). Effects of perceptual fluency on affective judgments. Psychological Science, 9(1), 45-48.

Smith, A. (2014, April 3). Older adults and technology use. Pew Research Internet Project. Retrieved April 30, 2014, from http://www.pewinternet.org/2014/04/03/older-adu lts-and-technology-use/

Span, P. (2013, April 8). Online habits coming slowly to older adults. The New York Times. Retrieved March 15, 2014, from http://newoldage.blogs.nytimes.com/2013/ 04/08/online-habits-coming-slowly-to-older-adults/?_ph $\mathrm{p}=$ true \&_type $=$ blogs \&_r $=0$

Statistics Korea. (2013). 2013 statistics on the aged. Statistics Korea. Retrieved January 23, 2014, from http://kostat.go.kr/portal/english/news/1/23/2/index.board?bmode $=$ read $\& b S e q=\& a S e q=309840 \&$ pageNo $=1 \&$ row $\mathrm{Num}=10$ \&navCount $=10 \&$ currPg $=\&$ sTarget $=$ title\&sTxt $=$

Tsarenko, Y., \& Strizhakova, Y. (2013). Coping with service failures. The role of emotional intelligence, self-efficacy, and intention to complain. European Journal of Marketing, 47(1/2), 71-92.

United Nations, Department of Economic and Social Affairs, Population Division. (2013). World Population Ageing 2013. ST/ESA/SER.A/348. United Nations. Retrieved March 15, 2014, from http://www.un.org/en/development/desa/populati-on/publications/pdf/ageing/WorldP opulationAgeing2013.pdf

Wei, L., \& Zhang, M. (2008, August 13). The impact of Internet knowledge on college students' intention to continue to use the Internet. Information Research, 13(3), paper 348. Retrieved April 21, 2014. from http://InformationR. net/ir/13-3/paper348.html

Wood, J. M. (2002). Age and visual impairment decrease driving performance as measured on a closed-road circuit. Human Factors, 44(3), 482-494.

You, E. Y., \& Lee, Y. R. (2010). Shopping value and satisfaction by presentation formats of apparel productsinformation on Internet shopping malls. Journal of the Korean Sociery of Clothing and Textiles, 34(1), 14-26.

Zajonc, R. B. (1997). Emotions. In D. Gilbert, S. T. Fiske, \& G. Lindzey (Eds.), Handbook of social psychology: Vol. 1 ( $4^{\text {th }}$ ed., pp. 591-632). New York: McGraw-Hill.

Zaichkowsky, J. L. (1986). Conceptualizing involvement. Journal of Advertising, 15(2), 4-14. 
Appendix. Measurement items used in the study

\begin{tabular}{|c|c|c|}
\hline & Measurement Items & $\begin{array}{c}\text { Cronbach's } \\
\alpha\end{array}$ \\
\hline \multirow{2}{*}{ Manipulation Check } & Pictures of the web site are of good quality. & \multirow{2}{*}{.75} \\
\hline & The web site was easy to read. & \\
\hline \multirow{4}{*}{$\begin{array}{l}\text { Fashion Involvement } \\
\text { (Fairhurst et al., 1989) }\end{array}$} & I am interested in fashion clothing. & \multirow{4}{*}{.87} \\
\hline & Fashion clothing means a lot to me. & \\
\hline & I always pay attention to what clothing style is in fashion. & \\
\hline & I feel great joy when I purchase or put on fashion clothing. & \\
\hline \multirow{6}{*}{$\begin{array}{c}\text { Internet Shopping } \\
\text { Self-Efficacy } \\
\text { (Eastin \& Larose, 2000) }\end{array}$} & $\begin{array}{l}\text { I feel confident navigating online stores to get the item that I want with better price or } \\
\text { quality. }\end{array}$ & \multirow{6}{*}{.96} \\
\hline & I feel confident finding various product information through online stores. & \\
\hline & I feel confident finding comparison information about products through an Internet store. & \\
\hline & I feel confident obtaining more additional services through searching online stores. & \\
\hline & I feel confident purchasing the item that I want efficiently from searching online stores. & \\
\hline & I feel confident searching lots of information in a limited time through online stores. & \\
\hline \multirow{3}{*}{$\begin{array}{l}\text { Web Attractiveness } \\
\text { (Aladwani \& Palvia, } \\
\text { 2002) }\end{array}$} & The web site is well designed. & \multirow{3}{*}{.78} \\
\hline & The web site uses fonts properly. & \\
\hline & The web site looks attractive. & \\
\hline \multirow{2}{*}{$\begin{array}{c}\text { Attitude } \\
\text { (Lee et al., 2008) }\end{array}$} & I like this web site. & \multirow{2}{*}{.91} \\
\hline & I have a good feeling toward this website. & \\
\hline
\end{tabular}

